\title{
Hypertonic Saline in Treatment of Pulmonary Disease in Cystic Fibrosis
}

\author{
Emer P. Reeves, Kevin Molloy, Kerstin Pohl, and Noel G. McElvaney \\ Respiratory Research Division, Department of Medicine, Royal College of Surgeons in Ireland, \\ Education and Research Centre, Beaumont Hospital, Dublin 9, Ireland \\ Correspondence should be addressed to Emer P. Reeves, emerreeves@rcsi.ie
}

Received 30 January 2012; Accepted 16 February 2012

Academic Editors: F. Becq and A. De Roux

Copyright (c) 2012 Emer P. Reeves et al. This is an open access article distributed under the Creative Commons Attribution License, which permits unrestricted use, distribution, and reproduction in any medium, provided the original work is properly cited.

\begin{abstract}
The pathogenesis of lung disease in cystic fibrosis is characterised by decreased airway surface liquid volume and subsequent failure of normal mucociliary clearance. Mucus within the cystic fibrosis airways is enriched in negatively charged matrices composed of DNA released from colonizing bacteria or inflammatory cells, as well as F-actin and elevated concentrations of anionic glycosaminoglycans. Therapies acting against airway mucus in cystic fibrosis include aerosolized hypertonic saline. It has been shown that hypertonic saline possesses mucolytic properties and aids mucociliary clearance by restoring the liquid layer lining the airways. However, recent clinical and bench-top studies are beginning to broaden our view on the beneficial effects of hypertonic saline, which now extend to include anti-infective as well as anti-inflammatory properties. This review aims to discuss the described therapeutic benefits of hypertonic saline and specifically to identify novel models of hypertonic saline action independent of airway hydration.
\end{abstract}

\section{Introduction}

Cystic fibrosis (CF) is a complex genetic disease with protean manifestations, the most important being increased risk of chronic lung disease resulting in terminal respiratory failure [1]. CF is an autosomal recessive disorder caused by mutations in the CF transmembrane conductance regulator (CFTR) chloride channel. More than 1000 mutations in the CFTR gene have been identified and result in misfolding of the CFTR protein. Reported mutations can be broadly categorised by class mutations which alter CFTR processing (Classes I, II, and V) as well as those resulting from dysregulated chloride secretion (Classes III, IV, and VI) (Figure 1). The commonest genetic defect in CFTR processing includes the $\Delta$ F508 mutation, of which $90 \%$ of CF suffers carry one copy [2]. Defects in CFTR protein function not only impact upon cAMP-dependent chloride secretion but also result in increased epithelial sodium channel- (ENaC-) mediated ion absorption in the superficial airway epithelium [3, 4]. As a consequence, increased water reabsorption across airway epithelial cells leads to extreme dehydration of the airway surface liquid layer, chronic mucostasis, and airflow obstruction [5]. This thickened mucus provides an ideal environment for bacterial infection in the respiratory tract with Staphylococcus aureus (S. aureus) being a major bacterial pathogen in early years and Pseudomonas aeruginosa ( $P$. aeruginosa) a prominent pathogen in adult patients $[6,7]$.

Dehydration of the airway surface liquid layer has been implicated as the primary initiating event in CF-related lung disease [9] and therapeutic interventions to improve mucus clearance is a cornerstone of treatment in CF [10]. Such interventions include regular chest physiotherapy, mucolytics such as dornase-alpha (DNase) [11] and also aerosolized hypertonic saline (HTS; $3 \%$ to $7 \% \mathrm{NaCl}$ ) [12]. HTS is defined as a solution possessing an osmotic pressure greater than that of physiologic isotonic salt solution $(0.9 \%$ $\mathrm{NaCl}$ ). Inhalation of HTS has been proposed to significantly improve mucociliary clearance [13] and the popularity of its use has increased on the basis of a number of clinical trials [14-17]. Several mechanisms have been proposed for the observed effectiveness including changes in the rheological characteristics of the airway mucus [18], increasing airway surface liquid hydration [19], inhibition of ENaC [20], as 


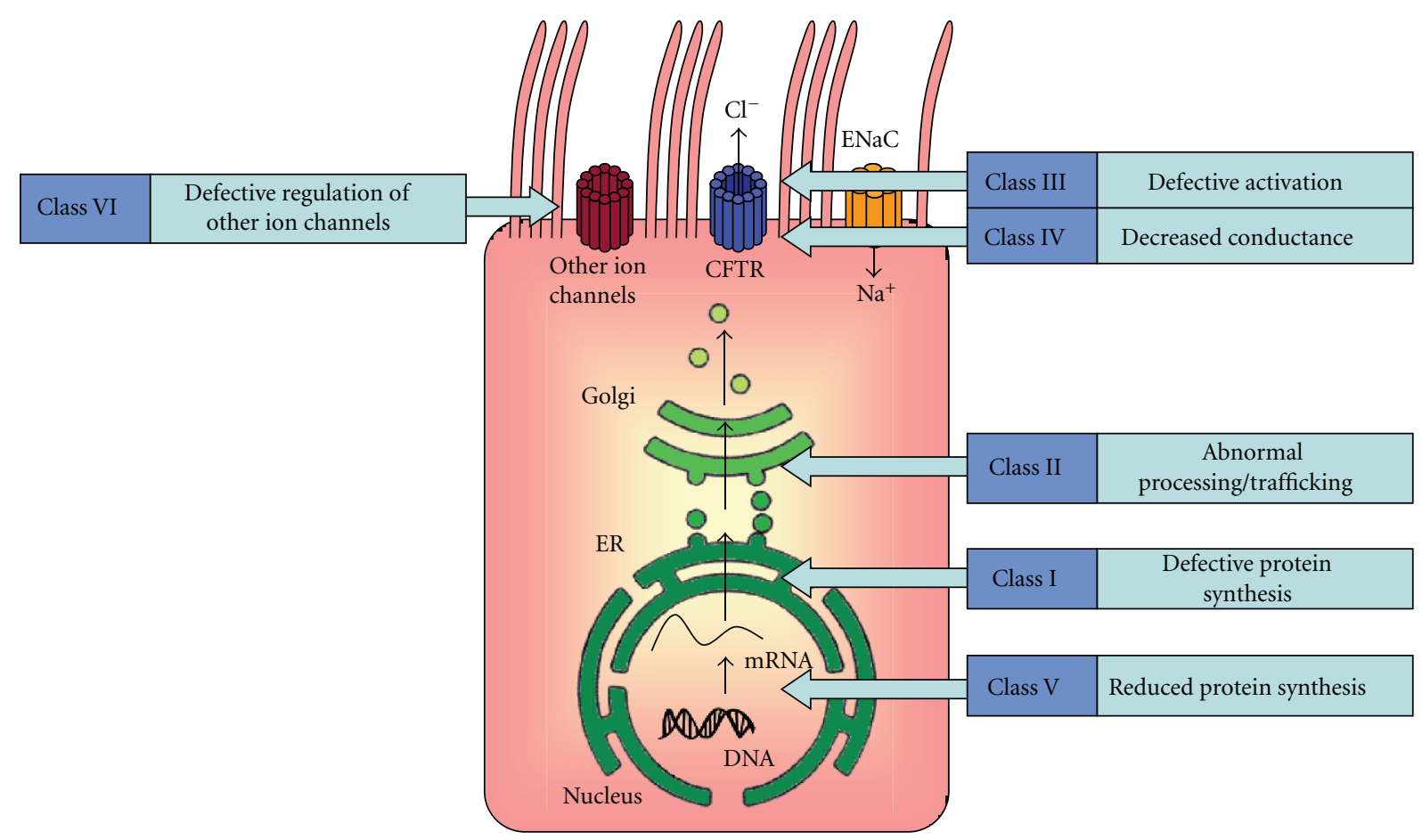

FIGURE 1: Classification of CFTR mutations. CFTR mutations are classified into six classes according to their effect on CFTR function. Class I mutations inhibit biosynthesis, while Class II mutations affect protein processing. Milder mutations such as Class III, IV, and VI impair CFTR channel function and Class V mutations affect gene expression, adapted from Allen (1999) [8].

well as immunomodulatory effects [21-23]. While a large controlled study reported mild positive effects of HTS on lung function [24], further studies have hurled it back into the limelight [25] and it is in this context that this review will compile the evidence for the use of HTS in treatment of individuals with $\mathrm{CF}$.

\section{Physical Properties of Airway Mucus in Cystic Fibrosis}

Within the normal lung, the mucous gel is largely made up of mucin glycoproteins which are either secreted or cell membrane tethered. Airway epithelial cells express three gelforming mucins including MUC2, MUC5AC, and MUC5B, although MUC5AC and MUC5B are thought to be the major gel-forming mucins in healthy airway secretions. While the molecular mass of mucins in CF and healthy control airway samples is comparable, the concentration of MUC5AC and MUC5B in CF sputum is markedly decreased [27]. This is of major importance and has prompted research aimed at investigating both the cause-and-effect relationship leading to thick purulent mucus in the $\mathrm{CF}$ airways. The primary cause of dehydrated thick mucus is increased water reabsorption across CFTR defective airway epithelial cells. However, a second reason for the thick viscous mucus in $\mathrm{CF}$ is the enrichment of anionic polyelectrolytes including DNA produced by colonizing bacteria or released from lysed inflammatory cells $[28,29]$. Moreover, F-actin released from necrotic cells within the $\mathrm{CF}$ airways plays a major role in the secondary polymer network of CF sputum [30]. By laser scanning confocal microscopy, copolymers of DNA and Factin have been observed which are thought to influence the viscoelasticity of CF sputa $[31,32]$. In addition, elevated concentrations of anionic glycosaminoglycans (GAGs) have been found in mucus samples from children with CF [33] (Figure 2). For example, significantly increased bronchial levels of hyaluronic acid have been reported [34], with sputum concentrations 100-fold higher than in acute bronchitis. Moreover, CF sputum has been shown to contain significantly elevated levels of chondroitin [35] and heparan sulphate [36] and in vitro enzymatic digestion of GAGs with chondroitinase $\mathrm{ABC}$ rather than protein digestion with trypsin decreased viscoelasticity of CF purulent sputa [37]. Of importance, studies have also shown that mutations in CFTR give rise to aberrant levels of sulphation. Particular changes in GAG chains and sulphation patterns may allow increased interactions, normally of ionic nature, with various proteins including antimicrobial peptides [21] and proinflammatory stimuli $[36,38-40]$. Data supporting this phenomenon have demonstrated synthesises of oversulphated glycoconjugates by CF tissue in organ culture [41] and airway epithelial cells $[42,43]$. Fundamentally, regardless of the exact or combined cause of increased viscosity, the thickened mucus within the CF airways becomes detached from the cilia and mucociliary transport is impaired, the major cause of lung morbidity and mortality in CF. HTS is thought to act by drawing water from CFTR defective airway epithelial cells, thereby rehydrating the periciliary layer [44] and supporting mucociliary clearance [25] (Figure 3). HTS is, therefore, one 


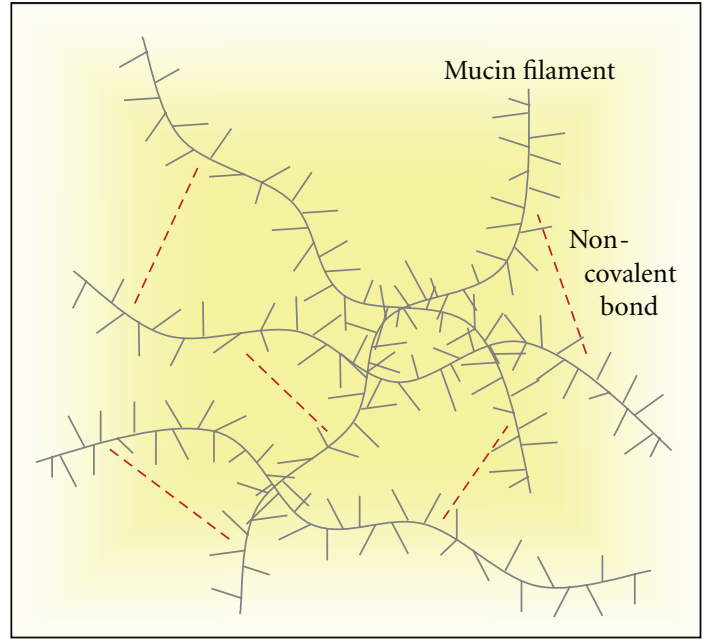

(a)

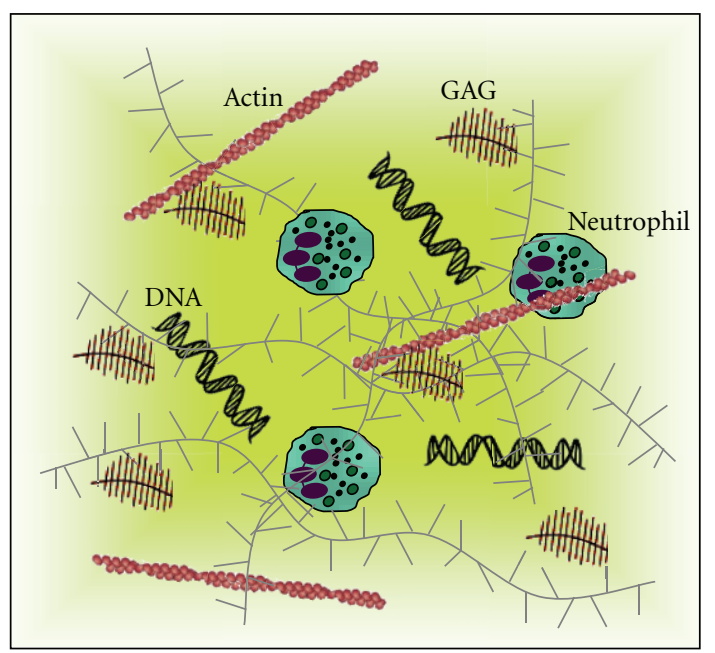

(b)

FIgure 2: Mucus properties in the CF lung. (a) Mucus in a healthy lung is made up of a network of mucin filaments consisting of highly glycosylated mucin monomers that are crosslinked by disulphide bonds. Mucin filaments are bound together by noncovalent bonds (red dotted lines) such as van der Waals forces. (b) In the CF airways, mucus viscosity is increased by DNA and actin (red) that are released from necrotic neutrophils and aggregate into bundles. Glycosaminoglycans (GAGs, depicted in brown) which are important for regulation of cell interactions have been found to be upregulated and altered in CF. Adapted from Rogers (2007) [26].

Healthy epithelia

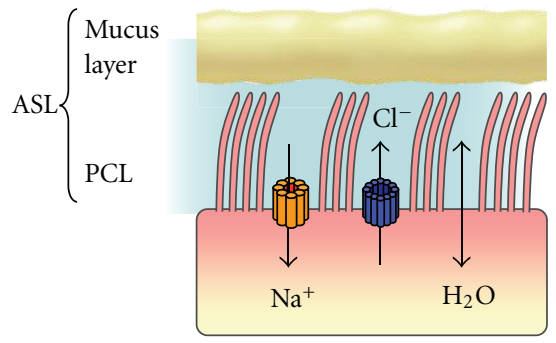

(a)

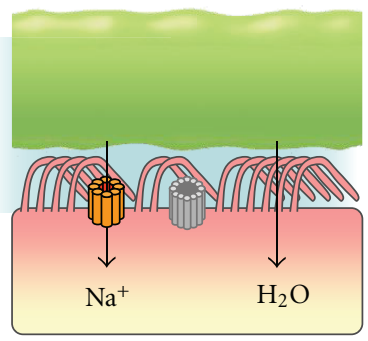

(b)

\section{CF epithelia following treatment with hypertonic saline}

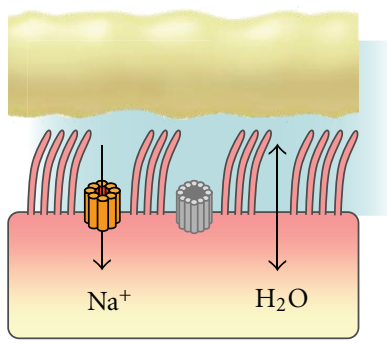

(c)

FIGURE 3: Effect of hypertonic saline on the airway surface liquid (ASL) in CF. (a) In healthy airway epithelia, CFTR is intact and plays a vital role in regulating hydration of the ASL that consists of the periciliary layer (PCL) and the mucus layer. (b) Due to defective CFTR in CF, Cl secretion is impaired and $\mathrm{Na}^{+}$absorption through $\mathrm{ENaC}$ is upregulated resulting in dehydration of the ASL with thick mucus accumulating and causing the PCL to collapse. (c) Treatment with hypertonic saline is proposed to reduce mucus viscosity and aids its clearance by various mechanisms. The high salt concentration encourages osmosis of water into the ASL and thereby rehydrates the mucus and partially restores the PCL allowing for easier clearance of mucus. Additionally, the high ionic strength weakens ionic bonds between negatively charged GAGs and thus reduces the viscosity of the mucus.

of the first treatments whose mechanism of action bypasses the basic CFTR defect.

\section{Hypertonic Saline in Treatment of CF Airway Disease}

In 2006, Elkins and colleagues from the National Hypertonic Saline in Cystic Fibrosis Study Group performed a trial of 164 patients who were randomised to receive 7\% HTS or isotonic $0.9 \%$ saline. Results revealed no significant difference in the rate of change of lung function (as measured by forced vital capacity and forced expiratory volume in one second
(FEV1)), yet the absolute difference in lung function between groups was significant $(P=0.03)$. Of major importance, this study offered the first evidence for the long-term efficacy of HTS and showed a marked reduction in the number of exacerbations over patients who received isotonic saline solution [24]. Likewise, in a study performed by Donaldson and colleagues (2006), patients who received HTS (7\% four times daily for 14 days with or without amiloride (inhibitor of $\mathrm{ENaC})$ ) demonstrated improved mucociliary clearance and FEV1 when given alone rather than in conjugation with amiloride [25]. The effect of HTS in this latter study could only be compared to baseline as no isotonic saline 
control group was included [25], however, their conclusions were echoed in a further study by use of radioaerosol technology [13]. Within this latter study, patients with CF treated with HTS had significantly increased mucociliary clearance compared to patients treated with amiloride or isotonic saline [13]. A further consideration when debating the effectiveness of HTS is the volume administered. In studies performed by Elkins et al., [24] and Donaldson et al., [25] 4 and $5 \mathrm{~mL}$ of HTS were aerosolized, respectively, and their studies recorded smaller improvements in lung function compared to Ballmann and von der Hardt [15] and Eng et al., [16] who delivered $10 \mathrm{~mL}$ of HTS. Moreover, in a recent stratified assessment of the impact of HTS on CF pulmonary exacerbations, Dmello et al., (2011) reviewed 340 cases of which 99 involved HTS treatment. By the use of multivariate logistic regression analysis, their results supported treatment with HTS in the context of reducing pulmonary exacerbations associated with CF lung disease [45].

HTS has been shown to increase mucociliary clearance in adults with CF $[13,25,44]$, but in contrast, did not significantly improve mucociliary clearance in children with CF (median age 10.5 years) [46]. The differences in therapeutic efficacy of HTS between adults and children may, however, relate to the degree of airway disease. Nevertheless, if HTS can improve mucociliary clearance by impacting upon the fundamental hydration defect, it may prove most successful in treatment of juvenile and young teenage patients before airway disease takes hold. To this end, in a recent study of 18 young participants (12-30 months of age) who received $7 \%$ HTS twice daily for 14 days, Rosenfeld and coworkers (2011) showed that HTS was well tolerated with high patient adherence [47]. In addition, lung clearance index, a measure of lung physiology derived from multiple breath washout tests, improved in paediatric patients (6-18 years) treated with $7 \%$ HTS compared to isotonic saline $(0.9 \%)$ solution [14]. Furthermore, a study assessing the safety and tolerability of inhaled HTS pretreated with nebulised beta adrenergic agonists (salbutamol) in preschool children (mean age $5.7 \pm 0.8$ years) and infants (mean age $1.6 \pm$ 1 years) with CF showed no clinically important decrease in FEV1, FVC, or $\mathrm{FEF}_{25-75}$ after HTS treatment. Only one patient had a clinically significant decrease $(>20 \%)$ in pulmonary function, however, this patient had a preexisting diagnosis of bronchial hyperactivity [48].

Induced cough may also be an important mechanism by which HTS improves mucociliary clearance in patients with CF. Patients treated with HTS have more cough episodes following treatment [48] and this may in itself improve mucociliary clearance by generating high sheer stress which promotes clearance of mucus from the airway surface [49]. The optimal dose of HTS is still a matter of debate with increasing doses (from 3\% to $7 \%$ ) requiring increasing nebulisation times, a potentially unrealistic treatment burden on patients [50], with compliance reported at only $64 \%$ [24]. On this point, coaerosolisation of $7 \%$ HTS with $0.1 \%$ hyaluronate has been shown to significantly improve tolerability and pleasantness compared to HTS alone [51]. Moreover, the effect of HTS on mucociliary clearance appears dose dependent. In a study performed by Robinson and colleagues (1997), the levels of sputum cleared over 90 minutes increased as the concentration of $\mathrm{NaCl}$ incrementally increased $(0.9 \%, 3 \%, 7 \%$, and $12 \%)$. However, patients experience considerable oropharyngeal irritation with concentrations approaching $12 \%$ making this the upper limit of tolerability in most patients.

Improvements in mucociliary clearance by HTS may provide a useful adjunct to improve the amount of sputum available for microbiological evaluation from patients such as those with mild disease or young children who have difficulty expectorating sputum. These patients often undergo flexible bronchoscopy and bronchoalveolar lavage to obtain adequate sample volumes for culture and sensitivity. Thus, HTSinduced sputum may be clinically useful by increasing the volume of expectorated sputum available for microbiological culture [52], as previously shown for children with CF [53].

\section{The Effect of Hypertonic Saline on Infection and Inflammation}

HTS does improve mucociliary clearance and lung function in patients with CF but a number of studies have also explored the possibility that HTS may impact upon the inflammatory response within the airways and in particular levels of the proinflammatory neutrophil chemokine, interleukin(IL)-8. In the long-term controlled trial of inhaled HTS in patients with CF performed by Elkins and colleagues (2006), measurements of the proinflammatory cytokines IL-6, IL-8, IL-10, and tumour necrosis factor-alpha (TNFalpha) were made in sputum at the time of screening and several later points until 48 weeks after the implementation of HTS nebulisation [24]. However, no significant difference was found in sputum levels between these groups (IL-6, $P=0.94$; IL-8, $P=0.36$; IL-10, $P=0.81$, and TNFalpha, $P=0.38$ ), although all samples tested were from the postrandomisation period and no direct comparison was made between pre- and postnebulisation sputum samples or from samples taken before starting HTS treatment. A second study by Aitken et al., (2003) measured IL- 8 and neutrophil numbers in CF sputum at 5 sequential time points during the 20 minutes after HTS nebulisation. Although the percentage of neutrophils decreased ( $89 \pm 5 \%$ to $86 \pm 4 \%$; $P=0.03$ ), the concentration of IL- 8 remained the same [54]. The beneficial effect of HTS on reducing airway neutrophil numbers was also observed in an animal model of induced lung injury, whereupon $7.5 \%$ HTS significantly reduced cell counts in bronchial lavage fluid from $46.8 \pm 4.4 \times 10^{3}$ to $24.5 \pm 5.9 \times$ $10^{3}$ cells $/ \mathrm{mL}(P<0.05)$.

Unexpectedly, it has also been shown that HTS conditions may actually increase IL- 8 production by CF gland cells via the NF- $\kappa$ B pathway [55] and IL- 8 expression in human bronchial epithelial cells via p38 mitogen-activated protein kinases activation [56]. Moreover, a study of individuals with asthma or COPD (10 patients in each group) revealed that inhalation of HTS caused low levels of inflammation in the airways with an increase in the levels of IL- 6 and TNF-alpha recorded in exhaled breath condensate [57]. In 
contrast, on a cellular level, the beneficial effects of HTS were found to include reduced arachidonic acid and leukotriene$\mathrm{B}_{4}$-induced priming of the respiratory burst of isolated neutrophils [58] and suppression of mTOR activity in mononuclear cells [59]. In additional studies, the beneficial effects of HTS were revealed as HTS increased levels of glutathione and thiocyanate which are protective against oxidants in the lung [60].

A further study by Suri et al., (2001) compared the effects of HTS and dornase-alpha on inflammatory mediators and found no significant difference in CF sputum IL-8 levels before and 18 hours after HTS nebulisation [17]. Indeed, it has been proposed that rhDNAse may actually promote inflammation by liberating cationic mediators bound to extracellular DNA such as proteases as well as active IL8 , which can potentiate neutrophilic inflammation causing further lung damage $[61,62]$. This latter point is obviously a concern, but research by our group has shown that when IL-8 is released from negatively charged matrices including GAGs this renders the chemokine susceptible to proteolysis and that there is a period of time during which IL-8 levels are significantly decreased after HTS treatment [23]. As per results demonstrated by Frevert et al., (2003) [63], within our study, we found that IL- 8 in CF bronchial lavage fluid is present in high molecular weight complexes involving GAGs including heparan and chondroitin sulphate [23]. By disrupting ionic interactions between IL- 8 and GAGs, HTS displaced IL-8 from GAG matrices rendering the chemokine susceptible to proteolytic degradation by neutrophil elastase thereby impacting upon inflammation [23]. Another key inflammatory mediator that is found in the CF lung and thought to play an important role in the pathophysiology of CF lung disease is the antimicrobial peptide cathelicidin (LL-37) [64, 65]. LL-37 demonstrates antimicrobial activity against an array of bacteria including $S$. aureus, Escherichia coli [66], and P. aeruginosa [21] and although present in high concentrations within the CF lung, the activity of LL-37 is inhibited by binding to GAGs [66]. Release of LL-37 within CF BALF was brought about by enzymatic digestion of GAGs (by hyaluronidase, chondroitinase $\mathrm{ABC}$, or heparinase II) thereby increasing the bactericidal efficiency of CF BALF against Pseudomonas and Staphylococcus bacteria [21]. In turn, HTS may also improve lung function by disrupting electrostatic interactions between GAGs and antimicrobial peptides. In support of this theory, in vivo LL-37 in CF sputum was liberated from GAGs following nebulised HTS (7\%) resulting in increased antimicrobial effect [21]. Thus, HTS therapy may directly impact upon the viability of bacteria within the CF airways. In fact, the effect of HTS on $P$. aeruginosa appears multifold, with high ionic strength affecting not only flagellin-mediated motility [22], but also viability of the mucoid subpopulation [67].

\section{How Does Hypertonic Saline Compare with Other Treatments?}

While HTS is cost effective [68] and has been proposed to enhance mucociliary clearance and lung function in $\mathrm{CF}$, other mucus mobilising therapies that have been evaluated include dornase-alpha [69], inhaled mannitol [70], gelsolin that severs actin filaments [30] and thiol derivatives such as n-acetylcysteine, although the clinical benefits of the latter treatment are unclear [71]. As high concentrations of DNA contribute to the viscosity of airway secretions, treatment with dornase-alpha, an enzyme which cleaves DNA polymers, results in a significant decrease in the viscosity of mucopurulent sputum [72]. Randomised controlled trials have demonstrated an improvement in FEV1 in patients treated with dornase-alpha [73-75] and although it appears more effective than HTS, some variation in the individual patient response was evident [76]. A small randomised study of 14 patients by Ballmann and Von Der Hardt, showed a mean increase in FEV1 of $7.7 \%$ in those treated with HTS in comparison to $9.3 \%$ in individuals treated with dornasealpha [15]. A larger study of 48 children randomised to 12 weeks of daily dornase-alpha $(2.5 \mathrm{mg})$, alternate day dornasealpha, and twice daily HTS (7\%) demonstrated a mean increase in FEV1 of 16\% (SD 25\%), 14\% (SD 22\%), and 3\% (SD 21\%) in each of the treatment groups, respectively. These studies strongly suggest that dornase-alpha is more effective than HTS in this setting [17].

Inhaled mannitol therapy has been proposed as an additional strategy to improve the airway surface hydration and mucociliary clearance in patients with CF. Mannitol is an osmotic agent with a high molecular weight which improves airway surface hydration by slow influx of water through a pericellular pathway [70]. Earlier studies have shown that mannitol improved mucociliary clearance in patients with asthma and non-CF-related bronchiectasis [77, 78]. A twoweek course of inhaled mannitol in patients with CF resulted in an increase in mean FEV1 from baseline of 7\% (95\% confidence interval, 3.3 to 10.7$)$ as well as mean $\mathrm{FEF}_{25-75}$ by $15.5 \%$ (95\% confidence interval, -6.5 to 24.6 ) compared with placebo [79]. While an international trial assessing the effect of inhaled dry powder mannitol on lung function in CF showed a sustained clinical benefit of mannitol irrespective of rhDNase [80], there have been no large randomised trials comparing the effect of HTS versus mannitol in the treatment of patients. A small study, however, comparing inhaled HTS and mannitol to placebo, showed that both HTS and mannitol demonstrated an improvement in bronchial mucus clearance in the postintervention period $(8.7 \pm 3.3 \%$ and $10.0 \pm 2.3 \%$ resp.) [81].

\section{Hypertonic Saline in Treatment of Other Airway Diseases}

While the focus of this review has been on CF-related bronchiectasis, non-CF-related bronchiectasis is a common clinical condition and is being recognised much more frequently with a reported prevalence in the United States of over 110,000. Whereas several studies have demonstrated benefits of HTS in CF, there are preliminary data regarding the therapeutic benefits of HTS in patients with non-CF bronchiectasis that are relevant to this review. In a doubleblinded study of 96 infants receiving repeated doses of 
TABLE 1: The reported effects of hypertonic saline on infection and inflammation.

\begin{tabular}{|c|c|c|c|}
\hline HTS treatment & Patients sample or cells & Effect after HTS & Reference \\
\hline 7\% HTS & Patients with CF & $\begin{array}{l}\text { Higher FEV1 and FVC, less pulmonary } \\
\text { exacerbations }\end{array}$ & Elkins et al. 2006 [24] \\
\hline $3 \%$ HTS & Sputum of patients with CF & $\begin{array}{l}\text { Surfactant protein A increased; } \\
\text { neutrophil counts, Staphylococcus aureus } \\
\text { and non-mucoid Pseudomonas slightly } \\
\text { decreased. }\end{array}$ & Aitken et al. 2003 [54] \\
\hline Hypertonic medium & $\begin{array}{l}\text { Human bronchial gland cells } \\
\text { from CF and healthy controls } \\
\text { (isolated from brushings) }\end{array}$ & $\begin{array}{l}\text { Increased } \mathrm{NaCl} \text { increased IL- } 8 \text {, but higher } \\
\text { in } \mathrm{CF} \text { cells (NF- } \kappa \mathrm{B} \text { pathway activated) }\end{array}$ & Tabary et al. 2000 [55] \\
\hline $\begin{array}{l}\text { Hyperosmolarity } \\
\text { ( } \mathrm{NaCl} \text { or mannitol, } \\
\text { up to } 6 \mathrm{x} \text { normal) }\end{array}$ & Human bronchial epithelial cells & $\begin{array}{l}\text { Increased IL- } 8 \text { release via p38 and JNK } \\
\text { pathway }\end{array}$ & Hashimoto et al. 1999 [56] \\
\hline $4.5 \%$ HTS & $\begin{array}{l}\text { Exhaled breath condensate of } \\
\text { patients with asthma or COPD } \\
\text { and healthy controls }\end{array}$ & $\begin{array}{l}\text { Greater IL- } 6 \text { and TNF-alpha } \\
\text { concentration, lower } \mathrm{pH} \text {. }\end{array}$ & $\begin{array}{l}\text { Carpagnano et al. } 2005 \\
\text { [57] }\end{array}$ \\
\hline Hypertonic medium & Peripheral blood neutrophils & $\begin{array}{l}\text { HTS inhibited neutrophil priming of } \\
\text { respiratory burst by } \mathrm{LTB}_{4} \text { and } \\
\text { arachidonic acid }\end{array}$ & Lee et al. 2011 [58] \\
\hline Hypertonic medium & $\begin{array}{l}\text { Peripheral blood mononuclear } \\
\text { cells }\end{array}$ & $\begin{array}{l}\text { Reduced LPS induced mTOR pathway } \\
\text { activation in HTS treated cells }\end{array}$ & Schaeffer et al. 2010 [59] \\
\hline 7\% HTS & Bronchial samples & Increased antioxidant levels in BAL fluid & Gould et al. 2010 [60] \\
\hline 7\% HTS & Sputum from patients with CF & $\begin{array}{l}\text { Decreased IL- } 8 \text { concentration in sputum } \\
\text { after HTS }\end{array}$ & Reeves et al. 2011 [23] \\
\hline 7\% HTS & Sputum from patients with CF & $\begin{array}{l}\text { LL-37 complexation to GAGs was } \\
\text { decreased after HTS and antimicrobial } \\
\text { properties of sputa restored }\end{array}$ & Bergsson et al. 2009 [21] \\
\hline $\begin{array}{l}2-7 \% \text { HTS in culture } \\
\text { medium }\end{array}$ & $\begin{array}{l}\text { Pseudomonas strain PA01 and } \\
\text { mucoid strain FRD1 }\end{array}$ & $\begin{array}{l}\text { Reduced motility and growth of all } \\
\text { strains tested }\end{array}$ & Havasi et al. 2008 [22] \\
\hline $\begin{array}{l}0-0.8 \mathrm{M} \mathrm{NaCl} \text { added } \\
\text { to medium }\end{array}$ & $\begin{array}{l}\text { Pseudomonas strain PA01 and } \\
\text { mucA mutant }\end{array}$ & $\begin{array}{l}\text { MucA mutant less resistant to osmotic } \\
\text { stress }\end{array}$ & Behrends et al. 2010 [67] \\
\hline
\end{tabular}

nebulised 3\% HTS or isotonic saline, those treated with HTS had a clinically relevant $26 \%$ reduction in hospital length of stay [82]. In a small study of 24 individuals with stable nonCF bronchiectasis, Kellett and colleagues (2005) reported that patients treated with 7\% HTS showed significantly higher sputum weights, reduced sputum viscosity, and ease of expectoration than those treated with isotonic saline $(P<0.0001)$. Median FEV1 and FVC demonstrated a statistically significant improvement $(P=0.043)$ [83]. In addition, a recent study by the same author reported that HTS was effective in decreasing sputum retention in patients with non-CF bronchiectasis, resulting in improved lung function and a reduction in annualised antibiotic usage and emergency health care utilisation [84].

Bronchiolitis is the leading cause of hospitalisation for infants involving a viral infection that begins as an upperrespiratory infection and then progresses to involve the lower small airways of the lung. A study by Al-Ansari et al., (2010) evaluated the clinical utility of HTS compared to isotonic saline in treatment of children with bronchiolitis and demonstrated that nebulisation with 5\% HTS improved the bronchiolitis severity score in patients with viral bronchiolitis compared to treatment with $0.9 \%$ and $3 \%$ saline [85]. HTS has been also been suggested for use in chronic pulmonary disease (COPD), asthma, and pneumonia [86-90]. A study into the safety of sputum induction in 100 individuals with COPD reported that HTS could be used by tailoring treatment to a patient's specific needs in moderate-to-severe COPD [90]. Moreover, in a multicenter study of 79 subjects with moderate-to-severe asthma, indices of inflammation (IL-8, myeloperoxidase, eosinophilic cationic protein, and neutrophil elastase) in HTS-induced sputum were as reproducible as those present in sputum postmethacholine $\mathrm{PC}_{20}$ treatment [87].

\section{Conclusion}

Therapies acting against airway mucus in CF include dextran, nacystelyn [91], and gelsolin [30] which possess mucolytic properties, but evidence that these agents cause sustained relief from airway obstruction in chronic lung disease is lacking. On comparing the beneficial effects of aerosol administration of dornase-alpha to HTS [17], dornase-alpha improved FEV1 and reduced the frequency of pulmonary exacerbations [73] but illustrated a combined effect when administered with HTS for the clearance of CF purulent sputa [18]. HTS treatment is associated with an improvement in lung function and marked benefits with respect to exacerbations (Table 1) [24, 25, 92, 93]. As 


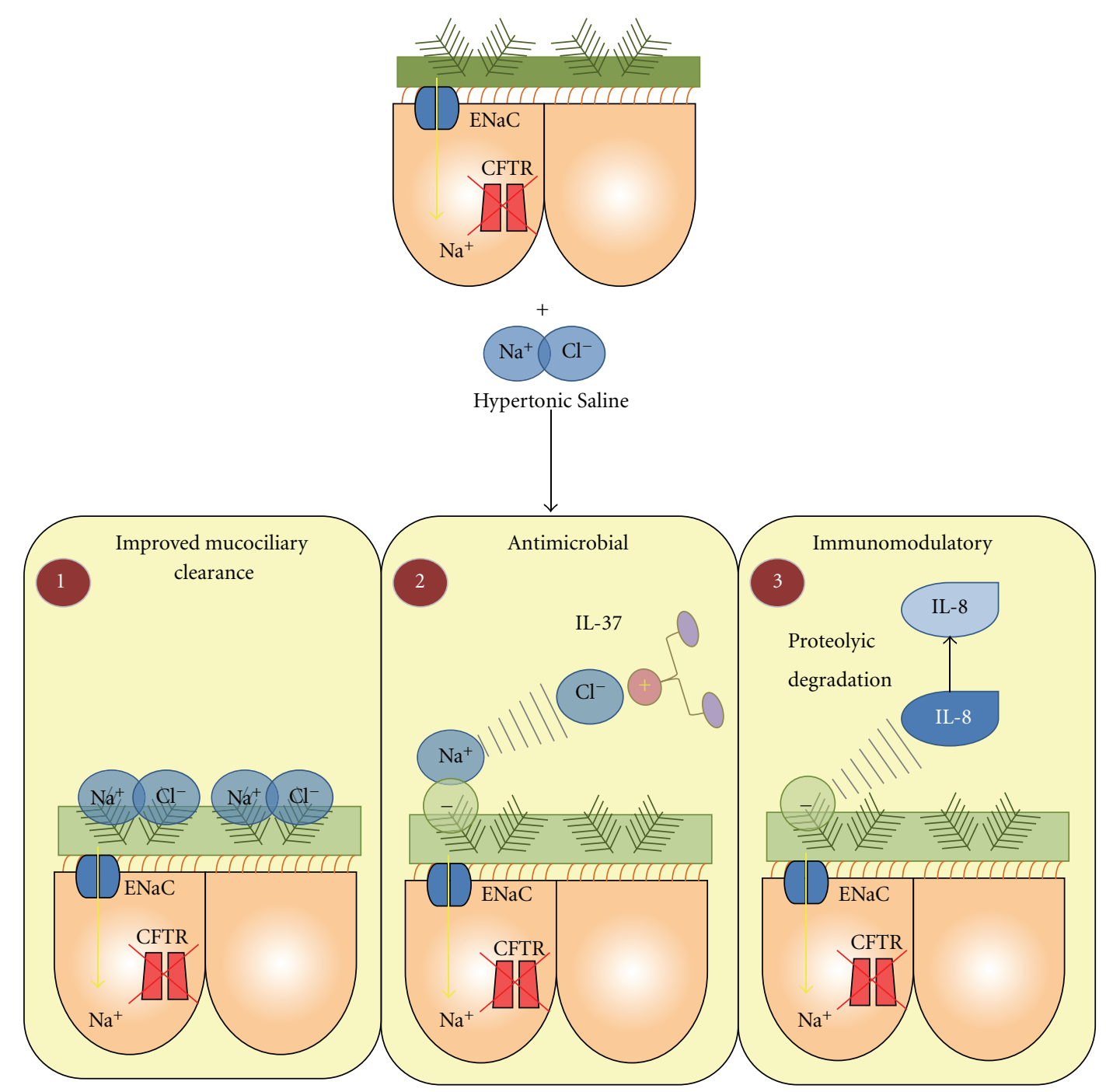

FIGURE 4: Schematic representation of the antimicrobial, immunomodulatory and mucolytic properties of HTS. (1) HTS draws water into the dehydated CF periciliary layer and improves mucus rheology and enhances mucociliary clearance. (2) LL-37, an antimicrobial protein that is inhibited by GAGs, is released by HTS via disruption of the electrostatic interaction between LL-37 and GAGs. (3) HTS liberates IL-8 from anionic matrices (GAGs) rendering the chemokine susceptible to proteolytic degradation by neutrophil elastase, thereby decreasing inflammation.

declared by Elkins and Bye (2006), "HTS appears broadly applicable as an inexpensive therapy for most patients with CF” [92] and of tremendous value on an individual basis for patients intolerant of dornase-alpha [12].

In a similar fashion to mannitol [94], the positive effect of nebulised HTS on mucociliary clearance is based on restoring the liquid layer lining the airways $[26,95]$. This simple scheme, which for many years has served as a satisfactory working hypothesis, may not be the full story. Studies are now revealing that HTS can also function by releasing essential antimicrobial and immune molecules from complexation with ionic matrices thus improving both antimicrobial efficiency and resolution of inflammation (Figure 4). These observations suggest that HTS has beneficial therapeutic effects other than simply increasing mucociliary clearance and thus further investigations of the potential mechanisms of this currently available therapy is crucially required.

\section{Acknowledgments}

The authors would like to thank the Health Research Board Ireland under Grant no. PHD/2007/11, the Medical Research Charities Group, Science Foundation Ireland under the Research Frontiers Programme (11/RFP/BMT/3094), and the Program for Research in Third Level Institutes administered by the Higher Education Authority for support.

\section{References}

[1] R. E. Wood, T. F. Boat, and C. F. Doershuk, "Cystic fibrosis," American Review of Respiratory Disease, vol. 113, no. 6, pp. 833-878, 1976. 
[2] J. Zielenski and L. C. Tsui, "Cystic fibrosis: genotypic and phenotypic variations," Annual Review of Genetics, vol. 29, pp. 777-807, 1995.

[3] R. C. Boucher, M. J. Stutts, and M. R. Knowles, " $\mathrm{Na}^{+}$transport in cystic fibrosis respiratory epithelia. Abnormal basal rate and response to adenylate cyclase activation," Journal of Clinical Investigation, vol. 78, no. 5, pp. 1245-1252, 1986.

[4] M. J. Stutts, C. M. Canessa, J. C. Olsen et al., "CFTR as a cAMP-Dependent regulator of sodium channels," Science, vol. 269, no. 5225, pp. 847-850, 1995.

[5] H. Matsui, B. R. Grubb, R. Tarran et al., "Evidence for periciliary liquid layer depletion, not abnormal ion composition, in the pathogenesis of cystic fibrosis airways disease," Cell, vol. 95, no. 7, pp. 1005-1015, 1998.

[6] D. J. Hassett, T. R. Korfhagen, R. T. Irvin et al., "Pseudomonas aeruginosa biofilm infections in cystic fibrosis: insights into pathogenic processes and treatment strategies," Expert Opinion on Therapeutic Targets, vol. 14, no. 2, pp. 117-130, 2010.

[7] B. C. Kahl, "Impact of Staphylococcus aureus on the pathogenesis of chronic cystic fibrosis lung disease," International Journal of Medical Microbiology, vol. 300, no. 8, pp. 514-519, 2010.

[8] E. D. Allen, "Cystic fibrosis: a decade of progress," Drugs of Today, vol. 35, no. 11, pp. 835-848, 1999.

[9] R. C. Boucher, "Evidence for airway surface dehydration as the initiating event in CF airway disease," Journal of Internal Medicine, vol. 261, no. 1, pp. 5-16, 2007.

[10] B. P. O'Sullivan and P. Flume, “The clinical approach to lung disease in patients with cystic fibrosis," Seminars in Respiratory and Critical Care Medicine, vol. 30, no. 5, pp. 505-513, 2009.

[11] A. P. Jones and C. Wallis, "Dornase alfa for cystic fibrosis," Cochrane Database of Systematic Reviews, vol. 3, p. CD001127, 2010.

[12] P. Wark and V. M. McDonald, "Nebulised hypertonic saline for cystic fibrosis," Cochrane Database of Systematic Reviews, no. 2, p. CD001506, 2009.

[13] M. Robinson, J. A. Regnis, D. L. Bailey, M. King, G. J. Bautovich, and P. T. P. Bye, "Effect of hypertonic saline, amiloride, and cough on mucociliary clearance in patients with cystic fibrosis," American Journal of Respiratory and Critical Care Medicine, vol. 153, no. 5, pp. 1503-1509, 1996.

[14] R. Amin, P. Subbarao, A. Jabar et al., "Hypertonic saline improves the LCI in paediatric patients with CF with normal lung function," Thorax, vol. 65, no. 5, pp. 379-383, 2010.

[15] M. Ballmann and H. Von Der Hardt, "Hypertonic saline and recombinant human DNase: a randomised cross-over pilot study in patients with cystic fibrosis," Journal of Cystic Fibrosis, vol. 1, no. 1, pp. 35-37, 2002.

[16] P. A. Eng, J. Morton, J. A. Douglass, J. Riedler, J. Wilson, and C. F. Robertson, "Short-term efficacy of ultrasonically nebulized hypertonic saline in cystic fibrosis," Pediatric Pulmonology, vol. 21, no. 2, pp. 77-83, 1996.

[17] R. Suri, C. Metcalfe, B. Lees et al., "Comparison of hypertonic saline and alternate-day or daily recombinant human deoxyribonuclease in children with cystic fibrosis: a randomised trial," The Lancet, vol. 358, no. 9290, pp. 1316-1321, 2001.

[18] M. King, B. Dasgupta, R. P. Tomkiewicz, and N. E. Brown, "Rheology of cystic fibrosis sputum after in vitro treatment with hypertonic saline alone and in combination with recombinant human deoxyribonuclease I," American Journal of Respiratory and Critical Care Medicine, vol. 156, no. 1, pp. 173177, 1997.
[19] R. Tarran, B. R. Grubb, D. Parsons et al., "The CF salt controversy: in vivo observations and therapeutic approaches," Molecular Cell, vol. 8, no. 1, pp. 149-158, 2001.

[20] A. Hebestreit, U. Kersting, and H. Hebestreit, "Hypertonic saline inhibits luminal sodium channels in respiratory epithelium," European Journal of Applied Physiology, vol. 100, no. 2, pp. 177-183, 2007.

[21] G. Bergsson, E. P. Reeves, P. McNally et al., "LL-37 complexation with glycosaminoglycans in cystic fibrosis lungs inhibits antimicrobial activity, which can be restored by hypertonic saline," Journal of Immunology, vol. 183, no. 1, pp. 543-551, 2009.

[22] V. Havasi, C. O. Hurst, T. C. Briles et al., "Inhibitory effects of hypertonic saline on P. aeruginosa motility," Journal of Cystic Fibrosis, vol. 7, no. 4, pp. 267-269, 2008.

[23] E. P. Reeves, M. Williamson, S. J. O’Neill, P. Greally, and N. G. McElvaney, "Nebulized hypertonic saline decreases IL-8 in sputum of patients with cystic fibrosis," American Journal of Respiratory and Critical Care Medicine, vol. 183, no. 11, pp. 1517-1523, 2011.

[24] M. R. Elkins, M. Robinson, B. R. Rose et al., "A controlled trial of long-term inhaled hypertonic saline in patients with cystic fibrosis," New England Journal of Medicine, vol. 354, no. 3, pp. 229-240, 2006.

[25] S. H. Donaldson, W. D. Bennett, K. L. Zeman, M. R. Knowles, R. Tarran, and R. C. Boucher, "Mucus clearance and lung function in cystic fibrosis with hypertonic saline," New England Journal of Medicine, vol. 354, no. 3, pp. 241-250, 2006.

[26] D. F. Rogers, "Mucoactive agents for airway mucus hypersecretory diseases," Respiratory Care, vol. 52, no. 9, pp. 1176-1193, 2007.

[27] M. O. Henke, A. Renner, R. M. Huber, M. C. Seeds, and B. K. Rubin, "MUC5AC and MUC5B mucins are decreased in cystic fibrosis airway secretions," American Journal of Respiratory Cell and Molecular Biology, vol. 31, no. 1, pp. 86-91, 2004.

[28] C. B. Whitchurch, T. Tolker-Nielsen, P. C. Ragas, and J. S. Mattick, "Extracellular DNA required for bacterial biofilm formation," Science, vol. 295, no. 5559, p. 1487, 2002.

[29] T. Brandt, S. Breitenstein, H. Von Der Hardt, and B. Tummler, "DNA concentration and length in sputum of patients with cystic fibrosis during inhalation with recombinant human DNase," Thorax, vol. 50, no. 8, pp. 880-882, 1995.

[30] C. A. Vasconcellos, P. G. Allen, M. E. Wohl, J. M. Drazen, P. A. Janmey, and T. P. Stossel, "Reduction in viscosity of cystic fibrosis sputum in vitro by gelsolin," Science, vol. 263, no. 5149, pp. 969-971, 1994.

[31] A. Kater, M. O. Henke, and B. K. Rubin, "The role of DNA and actin polymers on the polymer structure and rheology of cystic fibrosis sputum and depolymerization by gelsolin or thymosin beta 4," Annals of the New York Academy of Sciences, vol. 1112, pp. 140-153, 2007.

[32] P. Schwarzenberger, D. Lei, S. M. Freeman et al., "Antitumor activity with the HSV-tk-gene-modified cell line PA-1-STK in malignant mesothelioma," American Journal of Respiratory Cell and Molecular Biology, vol. 19, no. 2, pp. 333-337, 1998.

[33] T. N. Hilliard, N. Regamey, J. K. Shute et al., "Airway remodelling in children with cystic fibrosis," Thorax, vol. 62, no. 12, pp. 1074-1080, 2007.

[34] T. Schulz, U. Schumacher, C. Prante, W. Sextro, and P. Prehm, "Cystic fibrosis transmembrane conductance regulator can export hyaluronan,” Pathobiology, vol. 77, no. 4, pp. 200-209, 2010 . 
[35] H. Rahmoune, G. Lamblin, J. J. Lafitte, C. Galabert, M. Filliat, and P. Roussel, "Chondroitin sulfate in sputum from patients with cystic fibrosis and chronic bronchitis," American Journal of Respiratory Cell and Molecular Biology, vol. 5, no. 4, pp. 315320, 1991.

[36] N. Solic, J. Wilson, S. J. Wilson, and J. K. Shute, "Endothelial activation and increased heparan sulfate expression in cystic fibrosis," American Journal of Respiratory and Critical Care Medicine, vol. 172, no. 7, pp. 892-898, 2005.

[37] I. A. Khatri, K. R. Bhaskar, J. T. Lamont, S. U. Sajjan, C. K. Y. Ho, and J. Forstner, "Effect of chondroitinase ABC on purulent sputum from cystic fibrosis and other patients," Pediatric Research, vol. 53, no. 4, pp. 619-627, 2003.

[38] B. Goger, Y. Halden, A. Rek et al., "Different affinities of glycosaminoglycan oligosaccharides for monomeric and dimeric interleukin-8: a model for chemokine regulation at inflammatory sites," Biochemistry, vol. 41, no. 5, pp. 1640 1646, 2002.

[39] G. S. V. Kuschen, F. Coulin, C. A. Power et al., "Glycosaminoglycans interact selectively with chemokines and modulate receptor binding and cellular responses," Biochemistry, vol. 38, no. 39, pp. 12959-12968, 1999.

[40] S. Bhattacharyya, K. Solakyildirim, Z. Zhang, M. L. Chen, R. J. Linhardt, and J. K. Tobacman, "Cell-bound IL-8 increases in bronchial epithelial cells after arylsulfatase B silencing due to sequestration with chondroitin-4-sulfate," American Journal of Respiratory Cell and Molecular Biology, vol. 42, no. 1, pp. 51$61,2010$.

[41] R. C. Frates, T. T. Kaizu, and J. A. Last, "Mucus glycoproteins secreted by respiratory epithelial tissue from cystic fibrosis patients," Pediatric Research, vol. 17, no. 1, pp. 30-34, 1983.

[42] P. W. Cheng, T. F. Boat, K. Cranfill, J. R. Yankaskas, and R. C. Boucher, "Increased sulfation of glycoconjugates by cultured nasal epithelial cells from patients with cystic fibrosis," Journal of Clinical Investigation, vol. 84, no. 1, pp. 68-72, 1989.

[43] N. K. Mohapatra, P. W. Cheng, J. C. Parker et al., "Alteration of sulfation of glycoconjugates, but not sulfate transport and intracellular inorganic sulfate content in cystic fibrosis airway epithelial cells," Pediatric Research, vol. 38, no. 1, pp. 42-48, 1995.

[44] M. Robinson, A. L. Hemming, J. A. Regnis et al., "Effect of increasing doses of hypertonic saline on mucociliary clearance in patients with cystic fibrosis," Thorax, vol. 52, no. 10, pp. 900-903, 1997.

[45] D. Dmello, R. P. Nayak, and G. M. Matuschak, "Stratified assessment of the role of inhaled hypertonic saline in reducing cystic fibrosis pulmonary exacerbations: a retrospective analysis," British Medical Journal, vol. 1, article e000019, 2011.

[46] B. L. Laube, G. Sharpless, K. A. Carson, A. Kelly, and P. J. Mogayzel Jr, "Acute inhalation of hypertonic saline does not improve mucociliary clearance in all children with cystic fibrosis," BMC Pulmonary Medicine, vol. 11, artice 45, 2011.

[47] M. Rosenfeld, S. Davis, L. Brumback et al., "Inhaled hypertonic saline in infants and toddlers with cystic fibrosis: short-term tolerability, adherence, and safety," Pediatric Pulmonology, vol. 46, no. 7, pp. 666-671, 2011.

[48] E. P. Dellon, S. H. Donaldson, R. Johnson, and S. D. Davis, "Safety and tolerability of inhaled hypertonic saline in young children with cystic fibrosis," Pediatric Pulmonology, vol. 43, no. 11, pp. 1100-1106, 2008.

[49] R. Tarran, B. Button, M. Picher et al., "Normal and cystic fibrosis airway surface liquid homeostasis: the effects of phasic shear stress and viral infections," Journal of Biological Chemistry, vol. 280, no. 42, pp. 35751-35759, 2005.

[50] B. Enderby and I. Doull, "Hypertonic saline inhalation in cystic fibrosis-salt in the wound, or sweet success?" Archives of Disease in Childhood, vol. 92, no. 3, pp. 195-196, 2007.

[51] P. Buonpensiero, F. De Gregorio, A. Sepe et al., "Hyaluronic acid improves "pleasantness" and tolerability of nebulized hypertonic saline in a cohort of patients with cystic fibrosis," Advances in Therapy, vol. 27, no. 11, pp. 870-878, 2010.

[52] D. S. Armstrong, "In celebration of expectoration: induced sputum indices as outcome measures in cystic fibrosis," American Journal of Respiratory and Critical Care Medicine, vol. 168, no. 12, pp. 1412-1413, 2003.

[53] S. A. Ho, R. Ball, L. J. Morrison, K. G. Brownlee, and S. P. Conway, "Clinical value of obtaining sputum and cough swab samples following inhaled hypertonic saline in children with cystic fibrosis," Pediatric Pulmonology, vol. 38, no. 1, pp. 8287, 2004.

[54] M. L. Aitken, K. E. Greene, M. R. Tonelli et al., "Analysis of sequential aliquots of hypertonic saline solution-induced sputum from clinically stable patients with cystic fibrosis," Chest, vol. 123, no. 3, pp. 792-799, 2003.

[55] O. Tabary, S. Escotte, J. P. Couetil et al., "High susceptibility for cystic fibrosis human airway gland cells to produce IL-8 through the $\mathrm{I} \kappa \mathrm{B}$ kinase $\alpha$ pathway in response to extracellular $\mathrm{NaCl}$ content," Journal of Immunology, vol. 164, no. 6, pp. 3377-3384, 2000.

[56] S. Hashimoto, K. Matsumoto, Y. Gon, T. Nakayama, I. Takeshita, and T. Horie, "Hyperosmolarity-induced interleukin-8 expression in human bronchial epithelial ceils through p38 mitogen-activated protein kinase," American Journal of Respiratory and Critical Care Medicine, vol. 159, no. 2, pp. 634-640, 1999.

[57] G. E. Carpagnano, M. P. F. Barbaro, M. Cagnazzo et al., "Use of exhaled breath condensate in the study of airway inflammation after hypertonic saline solution challenge," Chest, vol. 128, no. 5, pp. 3159-3166, 2005.

[58] L. Lee, M. R. Kelher, E. E. Moore, A. Banerjee, and C. C. Silliman, "Hypertonic saline inhibits arachidonic acid priming of the human neutrophil," Journal of Surgical Research, vol. 174, no. 1, pp. 24-28, 2012.

[59] V. Schaeffer, S. Arbabi, I. A. Garcia et al., "Role of the mTOR pathway in LPS-activated monocytes: influence of hypertonic saline," Journal of Surgical Research, vol. 171, no. 2, pp. 769776,2010 .

[60] N. S. Gould, S. Gauthier, C. T. Kariya, E. Min, J. Huang, and B. J. Day, "Hypertonic saline increases lung epithelial lining fluid glutathione and thiocyanate: two protective CFTR-dependent thiols against oxidative injury," Respiratory Research, vol. 11, article 119, 2010.

[61] B. Perks and J. K. Shute, "DNA and actin bind and inhibit interleukin-8 function in cystic fibrosis sputa: in vitro effects of mucolytics," American Journal of Respiratory and Critical Care Medicine, vol. 162, no. 5, pp. 1767-1772, 2000.

[62] C. Vogelmeier and G. Doring, "Neutrophil proteinases and rhDNase therapy in cystic fibrosis," European Respiratory Journal, vol. 9, no. 11, pp. 2193-2195, 1996.

[63] C. W. Frevert, M. G. Kinsella, C. Vathanaprida et al., "Binding of interleukin-8 to heparan sulfate and chondroitin sulfate in lung tissue," American Journal of Respiratory Cell and Molecular Biology, vol. 28, no. 4, pp. 464-472, 2003. 
[64] N. C. Kaneider, A. Djanani, and C. J. Wiedermann, "Heparan sulfate proteoglycan-involving immunomodulation by cathelicidin antimicrobial peptides LL-37 and PR-39," The Scientific World Journal, vol. 7, pp. 1832-1838, 2007.

[65] W. Xiao, Y. P. Hsu, A. Ishizaka, T. Kirikae, and R. B. Moss, "Sputum cathelicidin, urokinase plasminogen activation system components, and cytokines discriminate cystic fibrosis, COPD, and asthma inflammation," Chest, vol. 128, no. 4, pp. 2316-2326, 2005.

[66] W. Barańska-Rybak, A. Sonesson, R. Nowicki, and A. Schmidtchen, "Glycosaminoglycans inhibit the antibacterial activity of LL-37 in biological fluids," Journal of Antimicrobial Chemotherapy, vol. 57, no. 2, pp. 260-265, 2006.

[67] V. Behrends, B. Ryall, X. Wang, J. G. Bundy, and H. D. Williams, "Metabolic profiling of Pseudomonas aeruginosa demonstrates that the anti-sigma factor MucA modulates osmotic stress tolerance," Molecular BioSystems, vol. 6, no. 3, pp. 562-569, 2010.

[68] R. Suri, L. J. Marshall, C. Wallis, C. Metcalfe, A. Bush, and J. K. Shute, "Effects of recombinant human DNase and hypertonic saline on airway inflammation in children with cystic fibrosis," American Journal of Respiratory and Critical Care Medicine, vol. 166, no. 3, pp. 352-355, 2002.

[69] R. C. Hubbard, N. G. McElvaney, P. Birrer et al., "A preliminary study of aerosolized recombinant human deoxyribonuclease I in the treatment of cystic fibrosis," New England Journal of Medicine, vol. 326, no. 12, pp. 812-815, 1992.

[70] M. T. Clunes and R. C. Boucher, "Front-runners for pharmacotherapeutic correction of the airway ion transport defect in cystic fibrosis," Current Opinion in Pharmacology, vol. 8, no. 3, pp. 292-299, 2008.

[71] E. F. Nash, A. Stephenson, F. Ratjen, and E. Tullis, "Nebulized and oral thiol derivatives for pulmonary disease in cystic fibrosis," Cochrane Database of Systematic Reviews, no. 1, p. CD007168, 2009.

[72] S. Shak, D. J. Capon, R. Hellmiss, S. A. Marsters, and C. L. Baker, "Recombinant human DNase I reduces the viscosity of cystic fibrosis sputum," Proceedings of the National Academy of Sciences of the United States of America, vol. 87, no. 23, pp. 9188-9192, 1990.

[73] H. J. Fuchs, D. S. Borowitz, D. H. Christiansen et al., "Effect of aerosolized recombinant human DNase on exacerbations of respiratory symptoms and on pulmonary function in patients with cystic fibrosis," New England Journal of Medicine, vol. 331, no. 10, pp. 637-642, 1994.

[74] B. W. Ramsey, S. J. Astley, M. L. Aitken et al., "Efficacy and safety of short-term administration of aerosolized recombinant human deoxyribonuclease in patients with cystic fibrosis," American Review of Respiratory Disease, vol. 148, no. 1, pp. 145-151, 1993.

[75] C. Ranasinha, B. Assoufi, S. Shak et al., "Efficacy and safety of short-term administration of aerosolised recombinant human DNase I in adults with stable stage cystic fibrosis," The Lancet, vol. 342, no. 8865, pp. 199-202, 1993.

[76] R. Suri, C. Wallis, A. Bush et al., "A comparative study of hypertonic saline, daily and alternate-day rhDNase in children with cystic fibrosis.," Health Technology Assessment, vol. 6, no. 34, pp. 1-60, 2002.

[77] E. Daviskas, S. D. Anderson, J. D. Brannan, H. K. Chan, S. Eberl, and G. Bautovich, "Inhalation of dry-powder mannitol increases mucociliary clearance," European Respiratory Journal, vol. 10, no. 11, pp. 2449-2454, 1997.
[78] E. Daviskas, S. D. Anderson, S. Eberl, H. K. Chan, and G. Bautovich, "Inhalation of dry powder mannitol improves clearance of mucus in patients with bronchiectasis," American Journal of Respiratory and Critical Care Medicine, vol. 159, no. 6, pp. 1843-1848, 1999.

[79] A. Jaques, E. Daviskas, J. A. Turton et al., "Inhaled mannitol improves lung function in cystic fibrosis," Chest, vol. 133, no. 6, pp. 1388-1396, 2008.

[80] D. Bilton, P. Robinson, P. Cooper et al., "Inhaled dry powder mannitol in cystic fibrosis: an efficacy and safety study," European Respiratory Journal, vol. 38, no. 5, pp. 1071-1080, 2011.

[81] M. Robinson, E. Daviskas, S. Eberl et al., "The effect of inhaled mannitol on bronchial mucus clearance in cystic fibrosis patients: a pilot study," European Respiratory Journal, vol. 14, no. 3, pp. 678-685, 1999.

[82] B. A. Kuzik, S. A. Al Qadhi, S. Kent et al., "Nebulized hypertonic saline in the treatment of viral bronchiolitis in infants," Journal of Pediatrics, vol. 151, no. 3, p. 266, 2007.

[83] F. Kellett, J. Redfern, and R. McL Niven, "Evaluation of nebulised hypertonic saline (7\%) as an adjunct to physiotherapy in patients with stable bronchiectasis," Respiratory Medicine, vol. 99, no. 1, pp. 27-31, 2005.

[84] F. Kellett and N. M. Robert, "Nebulised 7\% hypertonic saline improves lung function and quality of life in bronchiectasis," Respiratory Medicine, vol. 105, no. 12, pp. 1831-1835, 2011.

[85] K. Al-Ansari, M. Sakran, B. L. Davidson, R. El Sayyed, H. Mahjoub, and K. Ibrahim, "Nebulized $5 \%$ or 3\% hypertonic or $0.9 \%$ saline for treating acute bronchiolitis in infants," Journal of Pediatrics, vol. 157, no. 4, pp. 630-634, 2010.

[86] E. Bathoorn, J. Liesker, D. Postma, G. Koëter, A. J. M. Van Oosterhout, and H. A. M. Kerstjens, "Safety of sputum induction during exacerbations of COPD," Chest, vol. 131, no. 2, pp. 432-438, 2007.

[87] J. V. Fahy, H. A. Boushey, S. C. Lazarus et al., "Safety and reproducibility of sputum induction in asthmatic subjects in a multicenter study," American Journal of Respiratory and Critical Care Medicine, vol. 163, no. 6, pp. 1470-1475, 2001.

[88] E. Rand Sutherland, "Sputum induction in COPD-it's safe, so now what do we do?" Journal of Chronic Obstructive Pulmonary Disease, vol. 3, no. 2, pp. 73-74, 2006.

[89] O. Toungoussova, G. B. Migliori, M. P. Foschino Barbaro et al., "Changes in sputum composition during 15 min of sputum induction in healthy subjects and patients with asthma and chronic obstructive pulmonary disease," Respiratory Medicine, vol. 101, no. 7, pp. 1543-1548, 2007.

[90] A. M. Wilson, R. Leigh, F. E. Hargreave, M. M. M. Pizzichini, and E. Pizzichini, "Safety of sputum induction in moderateto-severe smoking-related chronic obstructive pulmonary disease," Journal of Chronic Obstructive Pulmonary Disease, vol. 3, no. 2, pp. 89-93, 2006.

[91] E. M. App, D. Baran, I. Dab et al., "Dose-finding and 24-h monitoring for efficacy and safety of aerosolized Nacystelyn in cystic fibrosis," European Respiratory Journal, vol. 19, no. 2, pp. 294-302, 2002.

[92] M. R. Elkins and P. T. P. Bye, "Inhaled hypertonic saline as a therapy for cystic fibrosis," Current Opinion in Pulmonary Medicine, vol. 12, no. 6, pp. 445-452, 2006.

[93] P. A. Wark, V. McDonald, and A. P. Jones, "Nebulised hypertonic saline for cystic fibrosis," Cochrane Database of Systematic Reviews, no. 3, p. CD001506, 2005. 
[94] P. J. Wills, "Inhaled mannitol in cystic fibrosis," Expert Opinion on Investigational Drugs, vol. 16, no. 7, pp. 1121-1126, 2007.

[95] R. C. Boucher, "Cystic fibrosis: a disease of vulnerability to airway surface dehydration," Trends in Molecular Medicine, vol. 13, no. 6, pp. 231-240, 2007. 


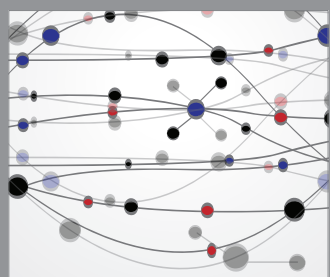

The Scientific World Journal
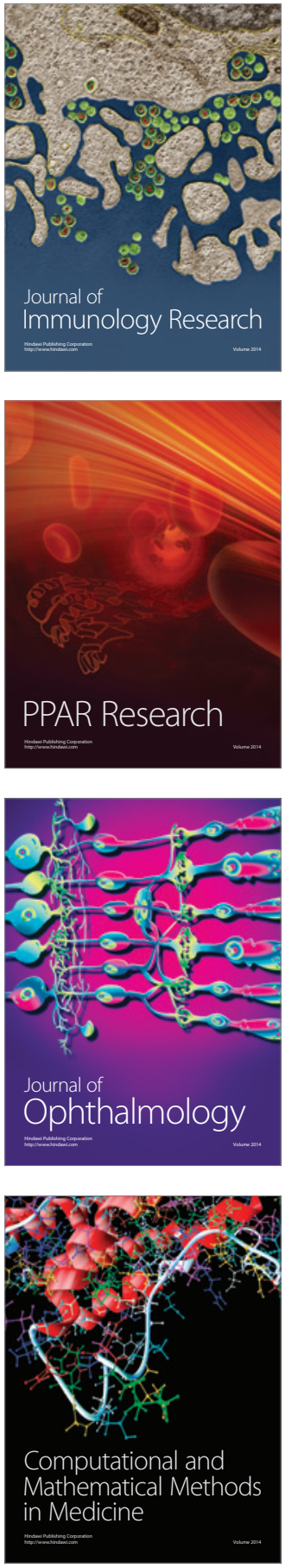

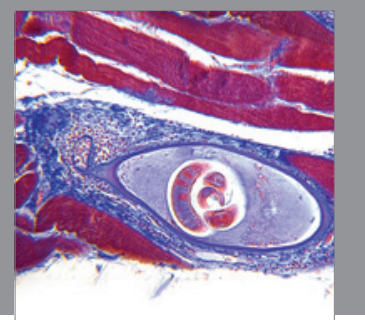

Gastroenterology

Research and Practice
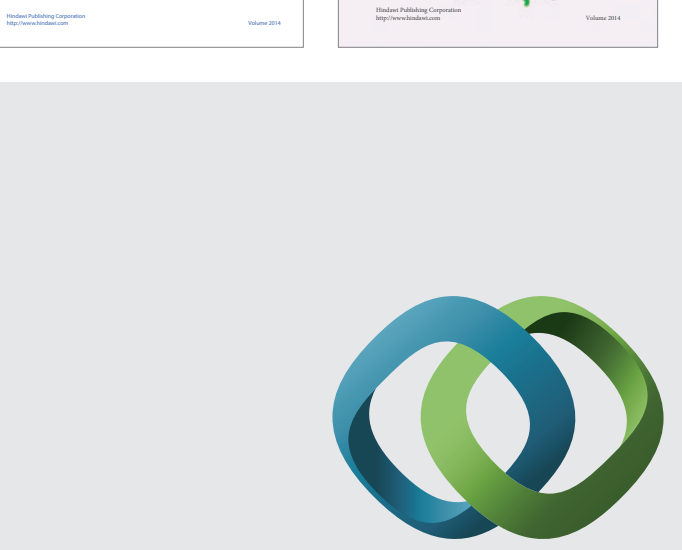

\section{Hindawi}

Submit your manuscripts at

http://www.hindawi.com
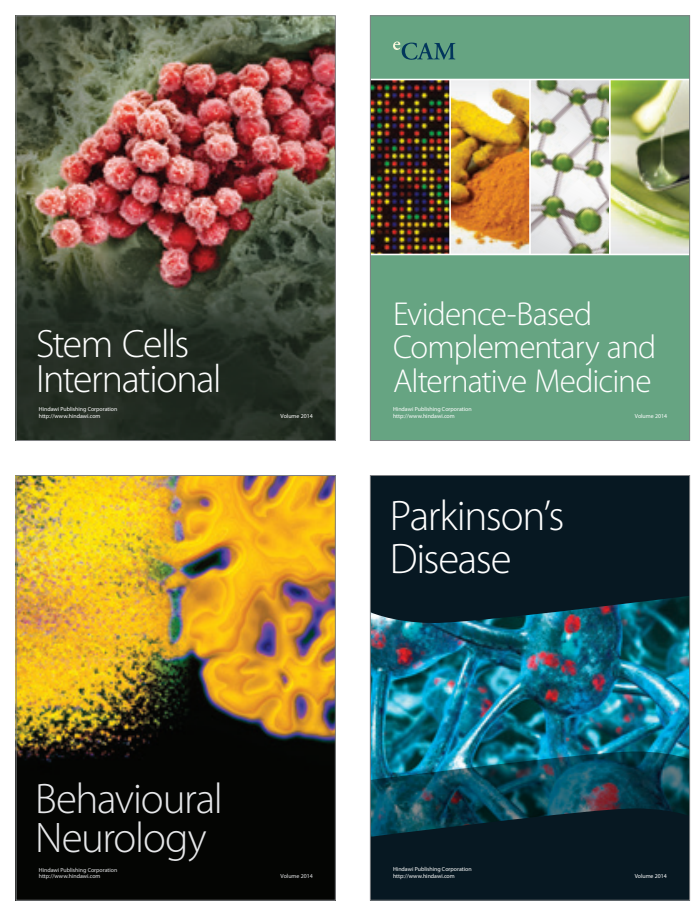

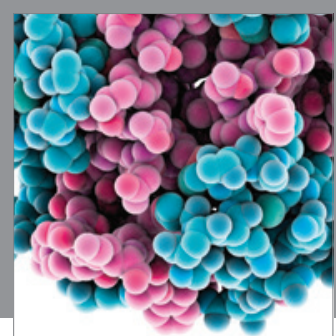

Journal of
Diabetes Research

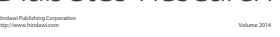

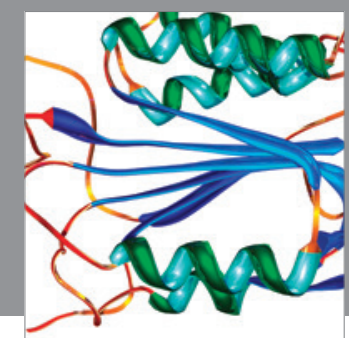

Disease Markers
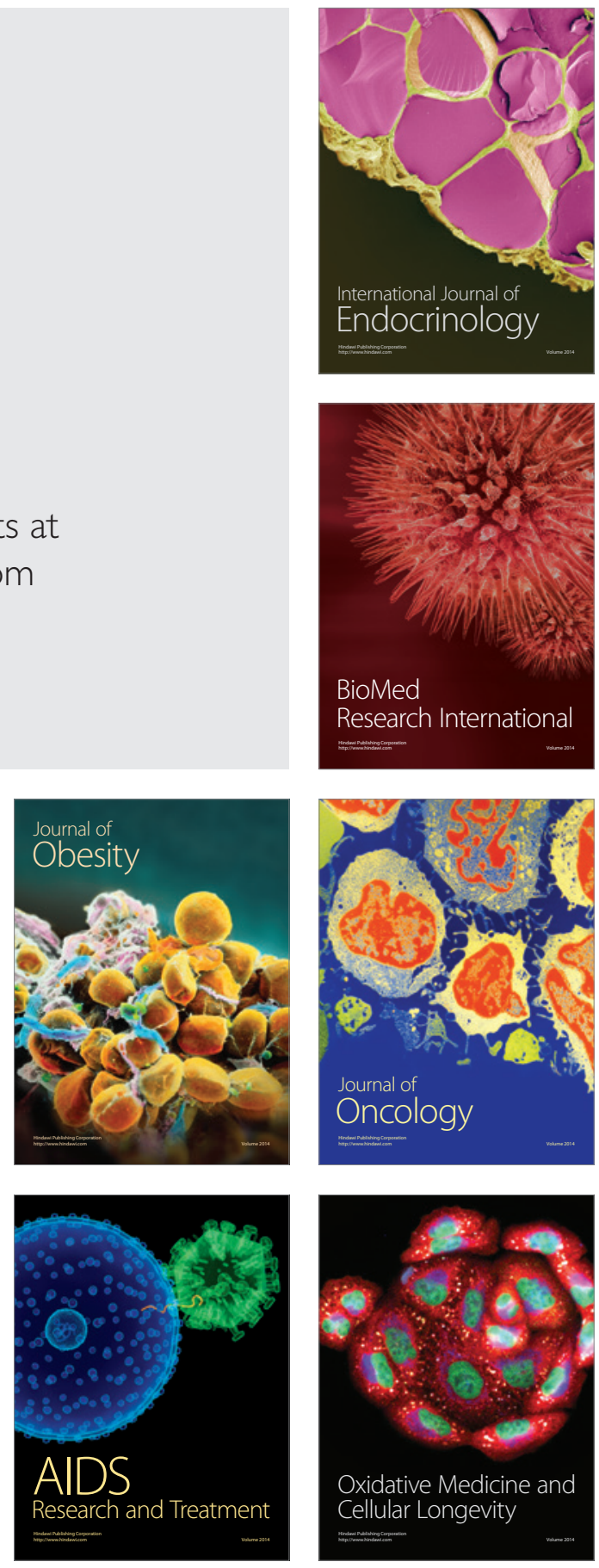